Georg Simmel

\title{
EXCURSO SOBRE O PROBLEMA: COMO É POSSÍVEL A SOCIEDADE? ${ }^{1}$
}

Tradução de Lenin Bicudo Bárbara

Kant somente pôde formular e responder a questão fundamental de sua filosofia - a saber: como é possível a natureza? -, porque, para ele, a natureza nada mais era do que a representação da natureza. Isso não significa apenas que, digamos, "o mundo seja minha representação", que nós, portanto, só podemos falar da natureza na medida em que ela seja um conteúdo da nossa consciência; mas sim que o que nós chamamos de natureza é uma maneira específica segundo a qual nosso intelecto compõe, ordena, modela as impressões sensíveis. Essas impressões "dadas" - das cores e gostos, dos sons e temperaturas, das resistências e odores -, que passam pela nossa consciência na sequência acidental da experiência subjetiva, não são ainda, por si mesmas, "natureza"; antes, elas vêm a ser natureza por meio da atividade do espírito, a qual as arranja em objetos e séries de objetos, em substâncias e propriedades, em associações causais. Segundo Kant, não há entre os elementos do mundo - assim como nos são imediatamente dados - aquela ligação que, por si só, faz deles a unidade compreensível, regular da natureza; ou, para ser mais preciso: não há entre eles justamente a ligação que denota o que há de natureza naqueles fragmentos do mundo em si incoerentes e surgidos desregradamente. A imagem de mundo kantiana se desdobra, assim, de modo a perfazer o mais peculiar dos contrastes: por um lado, as nossas impressões sensíveis são, para Kant, puramente subjetivas, já que dependem tanto da organização físico-psíquica (que poderia ser outra, em outros seres), 
quanto da casualidade do seu estímulo; e elas passam a ser "objetos" na medida em que são assimiladas pelas formas do nosso intelecto e por elas configuradas de modo a constituir uma regularidade firme e uma imagem coerente da natureza. Mas, por outro lado, aquelas impressões são, com efeito, o dado real, o conteúdo a ser irremediavelmente tomado do mundo, e a garantia de um ser independente de nós; de modo que agora são justamente aquelas formações intelectuais (que, das impressões, fazem objetos, nexos e legalidades) o que aparece como sendo o subjetivo, como sendo o que é trazido à tona por nós em oposição ao que recebemos da existência, como sendo as funções do próprio intelecto - funções que, elas mesmas imutáveis, teriam formado uma natureza outra em seu conteúdo a partir de um outro material sensível. A natureza é, para Kant, um determinado modo de conhecimento, uma imagem que se desenvolve por meio e no interior de nossas categorias cognitivas. Portanto, a questão - como a natureza é possível?, ou seja, quais são as condições que precisam estar presentes para que exista uma natureza? - se resolve, para Kant, mediante a procura das formas que constituem a essência do nosso intelecto e, com isso, realizam a natureza enquanto tal.

Seria presumível tratar de maneira análoga a questão acerca das condições apriorísticas na base das quais a sociedade é possível. Afinal, também no que concerne à sociedade são dados elementos individuais que permanecem, em certo sentido, sempre exteriores uns em relação aos outros - tal como se passa com as impressões sensíveis -, sofrendo sua síntese e, com isso, configurando a unidade de uma sociedade apenas por meio de um processo da consciência, o qual põe em relação, em determinadas formas e segundo determinadas regras, o ser individual de um elemento com o ser individual de outro. Há, contudo, uma diferença decisiva da unidade de uma sociedade que a opõe à unidade da natureza, que é esta: a unidade da natureza - de acordo com a perspectiva kantiana que aqui se pressupõe - se realiza exclusivamente no sujeito que observa, e é exclusivamente por ele engendrada junto a e a partir dos elementos sensíveis, eles mesmos desligados uns dos outros; ao passo que a unidade social de seus elementos, uma vez que estes são consciente e sinteticamente ativos, é realizada sem mais e não requer observador algum. Aquela proposição kantiana - segundo a qual a ligação nunca poderia estar situada na coisa em si, já que ela somente é realizada pelo sujeito - não se aplica à ligação social, que antes, com efeito, se realiza imediatamente nas "coisas", nesse caso almas individuais. Além disso, tal ligação continua sendo, enquanto síntese, algo puramente anímico, algo que não guarda nenhum paralelo com as formas espaciais e suas interações. Mas a unificação não requer, no caso da sociedade, fator algum que seja exterior a seus elementos, já que cada um deles exerce a função que a energia anímica do observador, no caso da natureza, cumpre frente ao que 
lhe é exterior: a unidade que está de fato em questão quando se trata da sociedade é a consciência de formar com os outros uma unidade. Isso obviamente não implica, de um lado, a consciência abstrata do conceito de unidade, mas sim as incontáveis relações singulares, o sentimento e o saber acerca desse determinar o outro e ser por ele determinado; e, de outro lado, tampouco impede que um terceiro, na posição de observador, realize entre as pessoas ainda uma outra síntese, só que agora, como aquela que ocorre entre os elementos no espaço, fundada unicamente nele. Se essa ou aquela província do ser aparente e observável será reunida numa unidade - isso não se resolve no seu conteúdo imediato e por excelência objetivo, mas, antes, é determinado mediante as categorias dos sujeitos e a partir das necessidades de conhecimento destes. A sociedade é, por sua vez, a unidade objetiva que prescinde de um observador que não esteja contido nela mesma.

Por um lado, as coisas na natureza estão bem mais dispersas umas em relação às outras do que o estão as almas; consoante a unidade de uma pessoa com outra, tal como se verifica na compreensão, no amor, na obra em comum - enfim, consoante essa unidade, não há, na realidade espacial (em que cada ser ocupa a sua porção do espaço, que a nenhum outro é dado então ocupar) em geral qualquer analogia. Mas, por outro lado, as frações da realidade espacial se combinam na consciência do observador formando uma unidade tal que o conjunto dos indivíduos não chega a formar. Assim, pelo fato de que os objetos da síntese são, nesse caso, seres autônomos, centros anímicos, unidades pessoais, eles resistem àquela fusão absoluta com a alma de um outro sujeito, diante da qual se entregam os objetos inanimados, aos quais falta um "eu". Dessa forma, certa quantidade de pessoas é uma unidade; mas uma unidade que, na realidade, é mais elevada, ainda que, idealmente, o seja em muito menor grau, se comparada àquela própria dos objetos, tal como: mesa, cadeiras, sofá, tapete e espelho, formando uma "decoração de interior", ou rio, pradaria, árvores e casa, constituindo uma "paisagem", ou as cores pintadas sobre uma tela, formando uma "imagem". ${ }^{2}$ Em suma: a sociedade é "minha representação" (ou seja, está fundada na atividade da consciência) num sentido bem diferente daquele em que o mundo exterior o é. Pois as outras almas têm para mim justamente a mesma realidade que eu tenho, uma realidade que é bastante diferente daquela de uma coisa material. Por mais que Kant tenha asseverado que a existência dos objetos no espaço haveria de ser tão certa quanto a minha própria existência, o que se entende aí como sendo a minha existência só podem ser os conteúdos particulares da minha vida subjetiva; pois o fundamento da representação em geral - ou seja, o sentimento do "eu" 3 existente - tem algo de incondicional e inabalável que nenhuma representação particular de uma exterioridade material chega a ter. Mas justamente essa certeza em relação ao nosso "eu" - seja ela passível ou não de ser fundamentada -, também a temos em relação ao fato do "tu"; 
e, seja como causa, seja como efeito dessa certeza, sentimos o "tu" como algo independente da representação que dele temos, algo que, exatamente como nossa própria existência, existe para si. Que esse para-si do outro não nos impeça de, contudo, fazer dele uma representação nossa; que algo que de modo algum está dissolvido no nosso representar, contudo, venha a se tornar um conteúdo, e, portanto, um produto desse representar - eis o problema e esquema psicológico e epistemológico mais profundo da socialização [Vergesellschaftung]. No interior da própria consciência, diferenciamos com bastante precisão entre, de um lado, a fundamentalidade do "eu", ou seja, o pressuposto de toda representação, que não tem parte na problemática do seu conteúdo (problemática essa que jamais se eliminará de uma vez por todas) - e, de outro lado, esse conteúdo, que, em conjunto com seu ir e vir, com sua inclinação para duvidar e para corrigir, apresenta-se como mero produto daquela força e existência absolutas e derradeiras do nosso ser anímico. Temos, porém, de transpor essas mesmas condições - ou melhor, a incondicionalidade do próprio "eu" - para as almas alheias, muito embora nós, no final das contas, também as representemos; para nós, as almas alheias têm aquele mesmo grau superlativo de realidade que nosso "eu" possui se comparado a seus próprios conteúdos, ou seja, temos a certeza de que elas também alcançam, se comparadas agora a seus respectivos conteúdos, aquele grau de realidade. Consoante essas circunstâncias, a presente questão (como é possível a sociedade?) tem um sentido metodológico completamente diverso do que a questão de Kant (como é possível a natureza?). Afinal, se o que responde a esta última questão são as formas do conhecimento mediante as quais o sujeito realiza a síntese dos elementos dados para que se constitua a "natureza", o que responde àquela primeira são as condições situadas a priori nos próprios elementos, elementos estes que realmente se interligam para que se constitua a síntese "sociedade". Em certo sentido, todo o conteúdo deste livro, 4 tal como se desenvolve tendo por base os princípios apresentados, é a preparação para a resposta a essa questão. Pois aqui o que se busca são os processos, em última análise realizados nos indivíduos, que condicionam sua existência enquanto sociedade - não como causas antecedentes no tempo desse resultado, mas sim como processos parciais dessa síntese que nós, de maneira condensada, denominamos "sociedade". Mas essa questão ainda há que ser entendida num sentido mais fundamental. Afirmei que a função de realizar uma unidade sintética, que, no caso da natureza, é atribuída ao sujeito que observa, haveria de ser atribuída, no caso da sociedade, aos elementos mesmos que a compõem. Ainda que a consciência de formar uma sociedade in abstracto não seja presente ao indivíduo, todo indivíduo sabe, afinal, que outros estão a ele ligados, ainda que esse saber que se volta para os outros tomando-os como socializados, ainda que esse conhecer que se volta para o complexo global tomando-o como uma sociedade - ainda 
que, enfim, esse saber e esse conhecer cuidem se realizar somente junto a conteúdos particulares, concretos. Mas o que se dá, neste caso, talvez não seja diferente do que se dá no caso da "unidade do conhecimento", de acordo com a qual nós, com efeito, procedemos ordenando, nos processos da consciência, um conteúdo concreto com outro, mesmo sem ter (a não ser em raras e tardias abstrações) uma consciência específica daquela unidade. A questão, agora, é esta: que é que se encontra, universalmente e a priori, na base; ou, que pressupostos precisam atuar para que os acontecimentos isolados, concretos, que se passam na consciência individual venham efetivamente a ser processos de socialização? E, ainda: quais elementos estão neles contidos que permitem que o seu resultado, abstratamente falando, seja a produção de uma unidade social feita a partir dos indivíduos? Os a priori sociológicos hão de ter o mesmo duplo significado daqueles que "tornam possível" a natureza: por um lado, eles determinarão, quer mais completa, quer mais deficientemente, os processos de socialização efetivos como funções ou energias da corrente anímica; por outro lado, eles são as pressuposições ideais, lógicas da sociedade perfeita (ainda que essa perfeição não venha, talvez jamais, a ser realizada). Analogamente, a lei causal, por um lado, vive e atua no processo efetivo do conhecimento; por outro, modela a forma da verdade, tomando-a como sistema ideal dos conhecimentos acabados - e o faz independentemente do fato de ser ou não realizada por aquela dinâmica temporal, relativamente acidental e anímica, e independentemente da maior ou menor convergência entre essa verdade que atua na consciência e aquela idealmente válida.

Se a investigação das condições do processo de socialização deve ou não deve ser denominada epistemológica - essa é uma questão meramente terminológica, já que as construções que se erguem a partir dessas condições e que são normatizadas por suas formas não constituem conhecimentos, mas sim processos práticos e estados de existência. Ainda assim, isso a que aqui me refiro, isso que é devido examinar (quanto às suas condições) como sendo a noção genérica de socialização, é, sim, algo que diz respeito ao conhecimento: a consciência de se socializar ou de estar socializado. Talvez fosse até melhor chamar isso de que aqui se trata de um saber, e não de um conhecer. ${ }^{5}$ Pois, aqui, o sujeito não se encontra diante de um objeto do qual, pouco a pouco, haveria de capturar uma imagem teórica, mas antes aquela cons ciência da socialização é imediatamente o seu suporte, o seu significado interior. Trata-se aqui dos processos de interação [Wechselwirkung] que denotam, para o indivíduo, o fato de que ele está socializado - fato esse que, ainda quando não seja abstrato, há certamente de ser passível de expressão abstrata. Quais formas precisam estar na base, ou, quais categorias específicas o ser humano precisa, por assim dizer, carregar consigo para que essa consciência venha à tona, e quais são, por conseguinte, as formas que precisam 
servir de suporte à consciência que assim emerge (quer dizer: a sociedade enquanto um fato do saber) - a isso talvez se possa dar o nome de teoria do conhecimento da sociedade. No que segue, procuro fazer um esboço de algumas dessas condições ou formas de socialização que atuariam a priori - que, a bem dizer, não são nomeáveis com uma palavra, como o são as categorias kantianas -, como exemplo para tais investigações.

I A imagem que um homem obtém de outro a partir do contato pessoal é condicionada por certos desvios, que não são meras ilusões tiradas da experiência incompleta, da visão deficiente, de preconceitos de simpatia ou antipatia, mas sim alterações fundamentais da qualidade do objeto real. E, com efeito, esses desvios se manifestam, antes de tudo, em dois planos distintos. ${ }^{6}$ [a] Nós vemos o outro em alguma medida generalizado - talvez em razão de que não nos seja dado representar, em nós e de um modo completo, uma individualidade diferente da nossa. Cada imagem tirada de uma alma é determinada pela semelhança em relação a ela, e, apesar de que essa não seja, de modo algum, a única condição do conhecimento anímico (pois, de um lado, parece ao mesmo tempo necessária uma desigualdade para que se obtenha distância e objetividade e, de outro, também uma faculdade intelectual que se mantenha para além tanto da igualdade, como da não-igualdade), o conhecimento completo pressuporia, de qualquer forma, uma igualdade completa. É como se cada pessoa tivesse em si um ponto de individualidade mais profundo, que nenhuma outra - na qual esse ponto é diverso quanto à qualidade - seria capaz de reconstruir interiormente. E a circunstância de que essa necessidade já não se coadune logicamente com aquela distância e avaliação objetiva sobre a qual, de resto, descansa a representação do outro, isso demonstra apenas que o saber completo acerca da individualidade do outro não nos é dado - e, assim, todas as relações dos homens uns com os outros são condicionadas pelos vários graus dessa privação. Agora, qualquer que seja a causa daquela necessidade, sua consequência é, em todo caso, uma generalização da imagem anímica do outro, uma diluição de seus contornos que adiciona, à singularidade dessa imagem, uma relação com outros. Nós representamos cada pessoa, com consequências específicas para o nosso comportamento prático em relação a ela, como o tipo de pessoa a que sua individualidade lhe permite pertencer; nós pensamos nela, com toda a sua singularidade, sob uma categoria universal que na verdade não a cobre completamente, e que ela tampouco cobre completamente - sendo que é nesse último sentido que se distingue a relação de que tratamos aqui daquela entre o conceito universal e a singularidade que se acha sob ele. Para conhecer o ser humano, nós não o vemos segundo sua individualidade pura, mas sim o suspendemos, elevamos ou até rebaixamos por meio de um tipo universal, com o qual da- 
mos conta dele. Mesmo quando essa conversão é tão imperceptível que já não mais podemos identificá-la imediatamente, e mesmo quando fracassam todos os conceitos mais abrangentes com que usualmente caracterizamos alguém (a saber: moral ou imoral, livre ou dependente, soberano ou servil etc.) - mesmo assim, interiormente designamos as pessoas segundo um tipo não nomeado, com o qual seu puro ser-para-si não coincide.

O que conduz a um nível mais profundo da discussão. [b] A partir, justamente, da singularidade acabada de uma personalidade, formamos uma imagem que não é idêntica ao que ela realmente é, mas que tampouco é um tipo universal; o que formamos é, antes, a imagem que essa pessoa passaria caso fosse, por assim dizer, completamente ela mesma, caso realizasse, em seus aspectos bons e ruins, a possibilidade ideal que existe em cada pessoa. Todos nós somos fragmentos, e fragmentos não só do homem universal, mas também de nós mesmos. Somos rudimentos não apenas do tipo "homem" em geral, não apenas de tipos como o do "bem" e o do "mal", ou como outros do gênero; 7 mas somos, ainda, rudimentos de nossa própria individualidade e singularidade (estas, em princípio, não mais passíveis de denominação), que envolvem, como se tivessem sido desenhadas com linhas ideais, a nossa realidade perceptível. O olhar do outro, entretanto, integra essa existência fragmentada de tal modo a fazer dela algo que nunca pura e completamente somos. Esse olhar é simplesmente incapaz de ver os fragmentos simplesmente um ao lado do outro, ou seja, do modo como estão efetivamente dados; em vez disso, assim como nós integramos o ponto cego em nosso campo de visão sem que dele tenhamos absolutamente nenhuma consciência, assim também formamos, a partir dessa existência fragmentada, o acabamento [Vollständigkeit] de sua respectiva individualidade. A prática da vida nos impele a configurar a imagem da pessoa unicamente a partir de seus fragmentos reais (ou seja, das partes dessa pessoa que conhecemos [wissen] de maneira empírica); mas essa mesma prática está baseada naquelas alterações e complementações, nas reformulações daqueles fragmentos dados que levam à universalidade de um tipo e ao acabamento da personalidade ideal.

Esse procedimento fundamental, mesmo que raramente consumado na realidade, opera no interior da sociedade existente como o a priori das interações subsequentes que se formam entre os indivíduos. Dentro de um círculo que abrange uma comunidade profissional ou de interesses, cada um dos membros vê os demais de um modo que não é puramente empírico, mas que está, antes, fundado em um a priori imposto por esse círculo a cada consciência que nele toma parte. Nos círculos de militares, religiosos, funcionários públicos, eruditos, familiares etc., cada um vê o outro partindo da premissa autoevidente de que: este aí é um membro do meu círculo. Depreende-se da base da vida em comum certas suposições, que fazem com que um enxergue o outro como que através de um véu. Esse véu, no entanto, não encobre, sim- 
plesmente, o que há de peculiar na personalidade, mas confere a ela uma nova forma, na medida em que toda a sua existência real e individual se funde a esse véu perfazendo uma construção unitária. Nós não vemos o outro pura e simplesmente como indivíduo, mas sim como colegas, camaradas ou correligionários; em suma, como coabitantes de um mesmo mundo particular - e essa pressuposição incontornável, que opera de maneira inteiramente automática, é um dos meios de conferir à personalidade e à realidade que se possui como parte da representação do outro a qualidade e a forma exigidas pela sua sociabilidade.

Isso é claramente válido também para a relação recíproca entre pessoas que pertencem a círculos distintos. O civil que trava conhecimento com um militar não pode se desvencilhar de uma vez por todas do fato de que esse indivíduo seja um militar. E ainda que o ser-militar possa fazer parte dessa individualidade, decerto não o faz da mesma e esquemática maneira segundo a qual sua imagem é preconcebida na representação do outro. E assim ocorre com os protestantes em relação aos católicos, os comerciantes em relação aos funcionários públicos, os leigos em relação aos sacerdotes etc.; nesses casos, estão presentes em toda parte velamentos do contorno da realidade por generalizações sociais, os quais, no interior de uma sociedade altamente diferenciada, em princípio barram o descobrimento desses contornos. Assim, a pessoa, na representação da pessoa, encontra desvios, diminuições e complementos - já que sempre a generalização é, a um só tempo, mais e menos que a individualidade - em relação a cada uma daquelas categorias que operam a priori, a saber: em relação a seu tipo como ser humano, à ideia de sua própria completude, à universalidade social a que ele pertence. Por sobre tudo isso se eleva, como princípio heurístico do conhecimento, a noção de sua determinação real, individual por excelência; todavia, e ainda que pareça que somente da obtenção dessa determinação real do indivíduo resulte uma relação completamente bem fundamentada para com ele, são, de fato, aquelas alterações e reconstruções (que impedem o conhecimento ideal dessa individualidade) elas mesmas já as condições que tornam possíveis as relações que nós conhecemos como puramente sociais - mais ou menos como, para Kant, são as categorias do entendimento (que formam objetos completamente novos a partir dos dados imediatos) que fazem, e elas apenas, do mundo dado um mundo permeável ao conhecimento.

II Outra categoria a partir da qual os sujeitos enxergam a si mesmos e uns aos outros, graças à qual é possível que tais sujeitos, assim formados, produzam a sociedade empírica - essa outra categoria pode ser formulada com a seguinte proposição, aparentemente trivial: cada elemento de um grupo não é apenas uma parte da sociedade; ele é, ainda, algo além disso. Trata-se de algo 
que opera como a priori social na medida em que a parte do indivíduo que não se volta para ou que não está absorvida pela sociedade não se encontra simplesmente desconectada, à margem daquela parte sua que é socialmente significativa, tampouco é algo exterior em relação à sociedade, algo para o qual a sociedade, quer queira, quer não, cede seu lugar. Antes, o fato de que o indivíduo em certos aspectos não seja um elemento da sociedade forma a condição positiva para que ele o seja em outros aspectos do seu ser: o modo do seu ser-socializado é determinado ou codeterminado pelo modo do seu não-ser-socializado. As investigações que se seguem terão como resultado alguns tipos, cujo significado sociológico está fixado (inclusive no que tem de mais essencial) pelo fato de que eles já estão, de alguma maneira, excluídos pela sociedade diante da qual sua existência tem significado: este é o caso do estrangeiro, do inimigo, do criminoso e até mesmo do pobre. Isto, contudo, não é válido apenas para esses tipos genéricos, mas também, em incontáveis modificações, para quaisquer manifestações individuais. Que nos encontremos compreendidos, a cada instante, por relações interpessoais, e que o conteúdo disso seja direta ou indiretamente determinado por tais relações - isso não está em desacordo com o que discutimos; pelo contrário: o caráter compreensivo da sociedade como tal afeta até mesmo seres que nela não estão completamente compreendidos. Nós sabemos do funcionário público que ele não é apenas funcionário público; do comerciante, que não é apenas comerciante; do militar, que não é apenas militar - e esse ser extrassocial (seu temperamento, o desenlace de seu destino, seus interesses e o valor de sua personalidade), ainda que pouco possa modificar a essência de sua atividade como funcionário público, comerciante ou militar, confere uma determinada nuance à pessoa para cada indivíduo com o qual esta se defronta, impregnando em sua imagem social imponderabilidades extrassociais. O trato interpessoal, assim como se verifica no âmbito das categorias sociais, seria como um todo diverso, caso cada um encarasse o outro somente como aquilo que ele é em sua respectiva categoria, como representante do papel social que lhe cabe naquele exato momento. Mas os indivíduos de fato se diferenciam entre si - exatamente como se diferenciam quanto às profissões ou quanto às situações sociais - de acordo com o grau daquele "algo-além-da-sociedade" que se possui ou se admite concomitantemente com seus conteúdos sociais. Um dos extremos dessa série de graus conforme a qual as pessoas se diferenciam é formado, por exemplo, nos casos do amor ou da amizade. Nesses casos, isso que o indivíduo reservou para si, ou seja, isso que está para além das formações e atividades voltadas para o outro, aproxima-se do valor limite zero, e o que há é uma única vida que pode, digamos, ser observada ou vivida desde duas perspectivas: ora desde a dimensão interior, do terminus a quo do sujeito; e ora (sem que na passagem de uma perspectiva a outra se altere em nada sua identidade), dessa vez tomando 
como orientação a pessoa amada, sob a categoria de seu terminus ad quem, que a absorve sem deixar resíduos. ${ }^{8} \mathrm{O}$ mesmo fenômeno do ponto de vista formal se oferece no caso do padre católico (ainda que, em tal caso, sob uma inclinação completamente diversa), cuja função religiosa recobre e subsome completamente o seu ser-para-si individual. No primeiro desses casos extremos [isto é, nos casos como o do amor e o da amizade], o "algo-além-da-sociedade" desaparece da atividade sociológica, porque seu conteúdo está completamente absorvido nesse voltar-se para uma outra pessoa; no segundo desses casos [isto é, nos casos como o do padre católico], porque falta, em princípio, o tipo de conteúdo que em geral lhe corresponde. ${ }^{9}$ No extremo oposto daquela série de graus, aparecem, por exemplo, as manifestações da cultura moderna, determinada pela economia monetária, em que a pessoa como produtora, compradora ou vendedora, e, em registro geral, realizadora de alguma coisa - se aproxima do ideal de objetividade absoluta; exceção feita às posições mais elevadas e de comando, a vida individual e o tom da personalidade como um todo desapareceram do que se realiza - as pessoas são apenas os suportes para uma equação (conduzida segundo normas objetivas) entre serviços realizados e serviços recebidos, e tudo que não se enquadre nessa objetividade pura efetivamente desaparece dela. Aquele "algo-além-da-sociedade" absorveu completamente em si mesmo a personalidade, junto com seu colorido específico, sua irracionalidade, sua vida interior, e deixou para aquelas atividades sociais somente as energias que lhe dizem especificamente respeito, isolando-as completamente.

É entre esses extremos que se movem os indivíduos sociais, e isso sempre de modo que as energias e determinações voltadas para o centro interior de cada um possuam algum significado para as atividades e disposições que se aplicam aos outros. Assim, no caso limite, até mesmo a consciência de que a atividade ou o temperamento social de uma pessoa seja algo distinto do resto dessa pessoa, e de que aquilo que ele é e significa para além de seu ser-social não tome parte em suas relações sociais - até mesmo essa consciência é, de um jeito ou de outro, uma influência positiva na atitude que o sujeito toma em relação ao outro e o outro, em relação a ele. O fato de que a vida não é plenamente social é o a priori da vida social empírica; nós não formamos nossas relações recíprocas simplesmente apesar de uma reserva negativa de uma parte da nossa personalidade, que fica de fora dessas relações: essa parte não influencia os processos sociais que transcorrem no interior da alma apenas mediante vínculos psicológicos universais; antes, a circunstância formal de que essa parte está de fora desses processos é justamente o que determina o modo dessa influência. - $O$ fato de que as estruturas da sociedade são feitas de seres que se encontram a um só tempo dentro e fora dela é o que também está na base de uma das mais importantes formações sociológicas, a saber: que pode ser que exista (e talvez que sempre 
exista, seja aberta, seja latentemente) entre uma sociedade e seus indivíduos uma relação como aquela entre dois partidos. Assim, a sociedade engendra aquele que é talvez o mais eminente (ou, pelo menos, o mais universal) dos desdobramentos de uma forma básica da vida em geral: que a alma individual jamais pode se incluir numa ligação sem, concomitantemente, situar-se para além dela; que ela não se alinha com ordem alguma sem que, ao mesmo tempo, a ela se oponha. Isso é válido desde os contextos transcendentes e mais amplamente universais até os mais singulares e acidentais. A pessoa religiosa sente-se completamente abarcada pelo ser divino, como se fosse apenas uma pulsação da vida divina - sua própria substância não possui reservas, e está mesmo entregue, em um estado de indiferenciação mística, à substância do absoluto. E, mesmo assim, para dar algum sentido a essa fusão, tal pessoa precisa preservar algum ser-si-mesmo, alguma contrapartida pessoal, um "eu" à parte, para quem a dissolução no ser divino seja uma tarefa sem fim, um processo, que não seria quer metafisicamente possível, quer perceptível como algo especificamente religioso, caso não derivasse de um ser-para-si do sujeito: o ser-um com Deus é condicionado, em seu significado, pelo ser-outro que não Deus. Situada para além dessa elevação rumo ao transcendente, a relação com a natureza em sua totalidade, que o espírito humano reclama para si ao longo de toda sua história, apresenta a mesma forma. Nós nos conhecemos, por um lado, na condição de seres integrados à natureza como um de seus produtos, que se encontra de igual para igual em relação a cada um dos demais produtos da natureza; um ponto a que sua matéria e energia chegam e depois deixam para trás, da mesma forma como circulam pela água corrente e pelas plantas que desabrocham suas flores. E ainda assim, por outro lado, a alma tem o sentimento de um ser-para-si independente de todas essas dissoluções e assimilações (sentimento esse designado pelo conceito - que, do ponto de vista lógico, é tão incerto - de liberdade), que se opõe e oferece resistência a todo esse mecanismo que, não obstante, é composto por nós mesmos; e que culmina no radicalismo implicado na ideia de que a natureza é somente uma representação nas almas humanas. Assim como, neste último caso, a natureza é encerrada, com toda a inegável regularidade que lhe é peculiar e com sua sólida realidade, no interior do "eu" - assim também esse "eu", por sua vez, com toda sua liberdade e seu ser-para-si, com sua oposição em relação à mera natureza, é, com efeito, um membro dela. É justamente nisso que consiste o nexo compreensivo da natureza - tal nexo coincorpora esse ser que é, diante dele, autônomo, e inclusive frequentemente hostil, e mesmo aquilo que, em conformidade a seu mais profundo sentimento vital, encontra-se fora de tal nexo precisa, apesar de tudo, ser um dos elementos que o compõem. Essa fórmula também se aplica à relação entre os indivíduos e os círculos particulares formados por seus vínculos sociais; ou, caso se resuma essa ideia no conceito ou sen- 
timento do ser-socializado em geral: à relação dos indivíduos pura e simplesmente. Nós nos conhecemos [wissen], por um lado, como produtos da sociedade: a série fisiológica dos antepassados; suas adaptações e aquilo que, neles, se fixou; as tradições de seu trabalho, de seu saber e de suas crenças; todo o espírito do passado, cristalizado em formas objetivas - isso tudo determina o arranjo e o conteúdo de nossas vidas, de tal maneira que seria possível questionar se acaso não seria o indivíduo, afinal, simplesmente um recipiente em que se misturam, em variadas medidas, elementos que já de antemão existiriam; pois, ainda que esses elementos fossem, no final das contas, produzidos por indivíduos, a contribuição de cada um deles haveria de ser de uma grandeza desprezível, e somente com a conjunção de seus elementos genéricos e sociais é que se produziriam os fatores cuja síntese constitui, aí sim, uma individualidade discernível. E por outro lado, nós nos conhecemos [wissen] como um membro da sociedade: nosso processo vital, bem como seu sentido e sua finalidade, está amarrado de forma tão indissociável à sociedade em seu caráter sincrônico, como o está no caso anterior, que diz respeito a seu caráter diacrônico. Assim como não temos, como seres naturais, um ser-para-nós, já que a cadeia dos elementos naturais passa através de nós da mesma forma como passa através de estruturas completamente inanimadas, e que a igualdade perante as leis naturais reduz toda a nossa existência a um mero exemplo de sua necessidade - assim também, como seres sociais, não vivemos em redor de um centro autônomo, senão que somos, a cada momento, compostos a partir de relações recíprocas para com outros; somos, pois, comparáveis à substância corpórea, esta que existe, para nós, apenas como a soma de diversas impressões sensíveis, e não como uma existência que se volta para si. Mas, afinal de contas, sentimos que essa difusão social não exaure completamente nossa personalidade, e esse sentimento não diz apenas respeito às já mencionadas reservas, ou seja, ao conteúdo singular cujo sentido e desenvolvimento se baseiam, desde o princípio, exclusivamente na alma individual e que em geral não tem lugar no contexto da sociedade; não diz respeito apenas à formação dos conteúdos sociais, cuja unidade na forma de alma individual não é por si só de natureza social, assim como a forma artística, na qual as impressões de cor se combinam sobre a tela, tampouco pode ser deduzida da natureza química das próprias cores. Antes, esse sentimento diz, sobretudo, respeito ao fato de que, ainda que o conteúdo global da vida possa ser totalmente esclarecido a partir dos antecedentes sociais e das relações recíprocas, pode ainda assim, ao mesmo tempo, ser considerado segundo a categoria da vida individual, ou seja, como vivência do indivíduo e como algo orientado para ele. Ambas são apenas categorias diferentes, sob as quais o mesmo conteúdo recai - assim como a mesma planta pode ser considerada quer do ponto de vista das condições biológicas de seu surgimento, quer de acordo com sua utilidade prática, quer, ainda, segundo sua significação estética. A perspectiva a partir da qual é ordenada e compreendida a existência individual pode ser as- 
sumida tanto do interior, como do exterior do indivíduo; a totalidade da vida, junto com todos os conteúdos seus que são passíveis de serem socialmente derivados, pode ser apreendida como sendo o destino centrípeto daquele que serve de suporte para a vida, assim como tal suporte, junto com todas as partes suas que são reservadas para o indivíduo, como sendo produto e elemento da vida social.

Com isso, o fato da socialização leva o indivíduo à situação dual de que parti: ele é, a um só tempo, abarcado pela socialização e a ela contrapos to; é, a um só tempo, um membro de seu organismo e, ele próprio, um todo orgânico fechado; um ser para a socialização e um ser para si. Mas o essencial e o sentido do a priori sociológico específico que nisso se baseia não é que o interior e o exterior entre indivíduo e sociedade sejam duas determinações existentes uma à parte da outra (ainda que possam, ocasionalmente, evoluir para esse estado de coisas, e até o ponto da hostilidade mútua), mas sim que designem a posição inteiramente unitária do homem que vive em sociedade. Sua existência não é apenas, se for para repartir seus conteúdos, em parte social e em parte individual; ela, antes, se encontra subsumida à categoria fundamental, estruturante, irredutível de uma unidade que nós não podemos mais expressar senão como síntese ou concomitância dessas duas determinações que, do ponto de vista lógico, se contrapõem uma à outra, a saber: a situação de membro e a de ser-para-si; a de ser produzido e abarcado pela sociedade, no primeiro caso, e da vida que parte do próprio centro e que se volta para o próprio centro, no segundo. Como estabeleci anteriormente, a sociedade não consiste, apenas, em seres que não estão, em parte, socializados; consiste, antes, em seres que percebem a si mesmos, de um lado, como existências inteiramente sociais e, de outro, mantendo o mesmo conteúdo, como existências inteiramente pessoais. E não se trata, aqui, de duas perspectivas que se encontram desconectadas uma à parte da outra, como quando, por exemplo, se olha para o mesmo corpo ora tendo por referência sua massa, ora sua cor; antes, as duas perspectivas formam a categoria sintética, a unidade a que damos o nome de ser social - assim como o conceito de causalidade é uma unidade a priori, ainda que esse conceito encerre elementos que são, em seus conteúdos, completamente diversos um do outro, a saber: os elementos de causa e os de efeito. O fato de dispormos dessa formação, ${ }^{\text {Io }}$ dessa capacidade para construir um conceito de sociedade a partir de criaturas que podem (cada uma delas) perceber a si mesmas como o terminus a quo e o terminus ad quem de seus destinos, desenvolvimentos e qualidades, e, portanto, um conceito tal de sociedade que leve justamente isso em conta; e, enfim, dessa capacidade para, em seguida, reconhecer [wissen] nesse conceito o terminus a quo e o terminus ad quem daquelas vitalidades e determinações da existência - esse é um dos a priori da sociedade empírica, que faz com que sua forma, assim como nós a conhecemos, seja possível. 
III A sociedade é uma estrutura composta por elementos desiguais. Afinal, mesmo nos casos em que tendências democráticas ou socialistas planejam ou, em parte, alcançam uma "igualdade", trata-se sempre e tão só da equivalência das pessoas, das realizações, das posições, enquanto uma igualdade dos homens em suas naturezas, conteúdos de vida e destinos permanece inteiramente fora de questão. E nos casos em que, por outro lado, um povo escravizado forma uma só massa, como nos grandes despotismos orientais, essa igualdade de todos com todos sempre afeta somente determinados aspectos da existência (o aspecto político ou o econômico, por exemplo), mas nunca sua totalidade; com tais existências - e o que segue não se aplica apenas ao lado interior da vida, mas também às suas relações recíprocas com outras existências -, advêm peculiaridades, relacionamentos pessoais e destinos vivenciados que haverão irremediavelmente de adquirir uma espécie de singularidade e infungibilidade. Caso se represente a sociedade como um esquema puramente objetivo, ela então se mostrará como uma ordem de conteúdos e realizações, relacionados uns aos outros em termos espaciais, temporais, conceituais e valorativos, e junto aos quais se pode, nessa medida, desconsiderar a personalidade, a forma do "eu" que serve de suporte para o caráter dinâmico da sociedade. Porém, caso aquela desigualdade dos elementos possibilite que cada uma daquelas realizações ou qualidades contidas nessa ordem se apresente como algo caracterizado individualmente e fixado inequivocamente em seu lugar, então a sociedade se mostrará como um cosmos, cuja multiplicidade (quanto ao seu ser e movimento) não pode ser desconsiderada, mas em que cada ponto somente pode ser arranjado e se desenvolver daquele determinado modo - devendo, em caso contrário, haver uma alteração na estrutura do todo. O que se disse a propósito da estrutura do mundo em geral - a saber: que nenhum grão de areia poderia ser diferentemente formado ou se encontrar numa situação diferente da que é o caso, sem que isso tenha por pressuposto e consequência uma alteração de toda a existência - se repete na estrutura da sociedade, quando vista como sendo um tecido de fenômenos determinados segundo suas qualidades. A imagem da sociedade assim obtida encontra uma analogia (que tem aqui o sentido de uma imagem em miniatura, infinitamente simplificada e, por assim dizer, estilizada) na burocracia, que consiste numa ordem definida de "posições", numa determinação prévia das realizações que, subtraída daqueles que em cada caso lhe servem de suporte, resulta em um encadeamento ideal; dentro desse encadeamento, cada novo indivíduo encontra um lugar inequivocamente determinado, que por assim dizer esperava por ele e em relação ao qual suas energias precisam entrar em harmonia. O que, no caso da burocracia, é a amarração consciente, sistemática dos conteúdos das realizações, é, na totalidade da sociedade, certamente um jogo confuso, inextricável de funções; as posições no interior da sociedade não são dadas por meio de uma 
vontade construtiva, mas sim se fazem compreensíveis apenas por meio da criação e da vivência reais dos indivíduos. E apesar dessa enorme diferença, apesar de tudo o que há de irracional, de imperfeito, e de tudo aquilo que, do ponto de vista valorativo, é corrompido - enfim, apesar de tudo isso que se verifica na sociedade histórica, sua estrutura fenomenológica (ou seja, a soma e a relação dos modos de existência e das realizações que cada um de seus elementos requer objetiva e socialmente) permanece sendo uma ordem de elementos, dentro da qual cada um ocupa um lugar individualmente determinado, um modo de coordenar funções e centros funcionais que são objetivos e, no que diz respeito a seus respectivos significados sociais, plenos de sentido (ainda que nem sempre plenos de valor); nessa estrutura, fica totalmente fora de consideração o que é puramente pessoal, interiormente produtivo, o que é reflexo e impulso do "eu" verdadeiro. Ou, expresso de outro modo: a vida da sociedade transcorre (quando vista não psicológica, mas sim fenomenologicamente, ou seja, puramente da perspectiva de seus conteúdos sociais como tais) como se cada elemento fosse de antemão determinado para ocupar seu devido lugar nessa totalidade; ela transcorre, de par com toda sua desarmonia em relação às demandas ideais, como se todos os seus membros mantivessem uma relação unitária uns com os outros, que haveria de referir cada um de seus membros - e isso justamente por ser ele esse membro em particular e não algum outro - a todos os demais, e todos os demais a cada um deles.

Torna-se visível, a partir daí, o a priori que devemos agora discutir e que significa, para o indivíduo, um princípio básico e a "possibilidade" de pertencer a uma sociedade. Que, por sua qualidade, cada indivíduo esteja espontaneamente referido a uma posição determinada no interior de seu meio social; e que essa posição a que ele idealmente pertence ainda se apresente no todo social - esse é o pressuposto para que o indivíduo possa viver sua vida em sociedade e que se pode designar como sendo o valor de universalidade da individualidade. Esse pressuposto independe do fato de ser ou não processado até o ponto de se consolidar numa consciência clara e conceitual, e também de encontrar ou não, no curso real da vida, sua realização - assim como o caráter a priori da lei causal independe, como pressuposto formador do conhecimento, do fato de que a consciência a formule em conceitos específicos, e também de que a realidade psicológica proceda ou não sempre em conformidade com ela. Nossa vida cognitiva tem por base o pressuposto de uma harmonia preestabelecida entre as nossas energias espirituais (por mais individualizadas que sejam) e a existência, que é exterior e objetiva; afinal, a existência permanece sendo sempre a expressão de um fenômeno imediato, pouco importando se ainda se pode (quer metafísica, quer psicologicamente) atribuir tal fenômeno à produção da existência pelo próprio intelecto. Assim, a vida social em si mesma se firma no pressuposto de uma harmonia 
fundamental entre o indivíduo e o todo da sociedade, ainda que esse não seja um obstáculo para as dissonâncias crassas da vida ética e da vida eudemonista. Caso a realidade social fosse estruturada por esse pressuposto básico de um modo irrestrito e isento de falhas, teríamos então a sociedade perfeita - ainda que não no sentido da perfeição ética ou eudemonista, mas sim no sentido conceitual: teríamos, por assim dizer, não a perfeita sociedade, mas sim a sociedade perfeita. Na medida em que o indivíduo deixe de realizar ou de encontrar realizado esse a priori da existência social (a saber: a correlação exaustiva de seu ser individual com o círculo que o envolve; a necessidade vinculante de sua particularidade, determinada por sua vida intrapessoal, para a vida do todo), ele não está, em sentido estrito, socializado, tampouco a sociedade é o círculo completamente fechado de interações que o seu conceito exprime.

Tal situação alcança um ápice já bastante evidente com a categoria da profissão. A Antiguidade decerto não tomou conhecimento desse conceito no sentido de uma diferenciação pessoal e de uma sociedade organizada pela divisão do trabalho. Mas o que há de fundamental no conceito de profissão, ou seja: que a ação socialmente efetiva seja a expressão unitária da qualificação interior ao sujeito; que o todo e o que há de permanente na subjetividade tornem-se, na prática, algo objetivo graças às suas funções na sociedade - isso, enfim, já existia na Antiguidade. A diferença é que essa relação era, então, realizada junto a um conteúdo mais perfeitamente homogêneo; seu princípio aparece na formulação aristotélica segundo a qual uns eram destinados a $\delta o v \lambda \varepsilon v ́ \varepsilon ı v$, enquanto outros a $\delta \varepsilon \sigma \pi$ ó $\varepsilon \imath v .{ }^{\text {II }}$ Desdobrado numa forma mais eleva$\mathrm{da}$, o conceito apresenta a seguinte estrutura, que lhe é peculiar: de um lado, a sociedade produz e fornece uma "posição" em seu interior que, embora seja diferente das outras em seu conteúdo e em seu contorno, pode ser, em princípio, ocupada por muitos e é algo (por assim dizer) anônimo; e, por outro lado, essa posição, apesar de seu caráter de universalidade, é ocupada pelo indivíduo por conta de um "chamado" interior, de uma qualificação sentida como algo inteiramente pessoal. Para que possa existir, em geral, uma "profissão", é preciso que se apresente (qualquer que seja sua origem) aquela harmonia entre, de um lado, a estrutura e o processo vital da sociedade e, de outro, as qualidades e os impulsos individuais. É nessa harmonia, entendida como pressuposto universal, que em última análise se baseia a ideia de que haveria, para cada personalidade, uma posição e algo a realizar dentro da sociedade, para a qual ela é "nomeada", ${ }^{\text {I2 }}$ bem como o imperativo de procurá-la o quanto for preciso até encontrá-la.

A sociedade empírica só se torna "possível" por meio desse a priori que culmina no conceito de profissão e que, a bem dizer, assim como os que se tratou anteriormente, não pode ser designado por uma simples palavra, como o podem as categorias kantianas. Os processos da consciência nos quais se 
realiza a socialização - a saber: a unidade composta pelas variedades, a determinação recíproca dos indivíduos, o significado mútuo que o indivíduo tem para a totalidade dos demais e que esta tem para o indivíduo - transcorrem sob o efeito do pressuposto absolutamente básico, que não é consciente de forma abstrata, mas se expressa na realidade prática, segundo o qual a individualidade de alguém em particular encontra uma posição no interior da estrutura da universalidade, e mesmo de que, numa certa medida, essa estrutura se apoia de antemão no indivíduo e em suas realizações - a despeito do que há, nesse indivíduo, de imponderável. O nexo causal que entrelaça cada elemento social no ser e fazer de todos os demais elementos e, assim, realiza a rede externa da sociedade - esse nexo se transforma em um nexo teleológico assim que observado do ponto de vista de seus suportes individuais, de seus produtores, que se sentem como "eus" e cujo comportamento brota do solo da personalidade que existe para si e que determina a si mesma. Que aquela totalidade fenomênica se conforme ao propósito dessas individualidades que, por assim dizer, dela se aproximam desde fora; que ela forneça um lugar para os processos vitais interiormente determinados desses indivíduos, no qual a particularidade destes se torna uma parte essencial para a vida do todo - é isso o que, como categoria fundamental, confere à consciência do indivíduo a forma que o designa a ser um elemento social.

Georg Simmel (I858-1918) foi um influente pensador alemão, e é hoje considerado um dos clássicos da sociologia.

Sua contribuição para o estabelecimento da sociologia na Alemanha foi decisiva. É autor de vasta e diversificada obra, dentre as quais é possível destacar Philosophie des Geldes (Filosofia do dinheiro), primeiro publicada em I90o, e Soziologie (Sociologia), de I908. 


\section{NOTAS}

I Tradução do original Simmel, Georg. (I992 [I908]). Exkurs über das Problem: Wie ist Gesellschaft möglich? In: Soziologie: Untersuchungen über die Formen der Gesellschaftung (Georg Simmel Gesamtausgabe, v. I I). Frankfurt am Main: Surhkamp.

2 Os grifos em itálico foram acrescentados por mim, tendo em vista uma melhor organização dos elementos da frase; nesse ponto, adotei uma solução semelhante à da tradução para o espanhol, disponível em Simmel (i998).

3 Optei por colocar entre aspas todas as ocorrências aos pronomes pessoais "eu" e "tu" presentes no excurso; tais aspas não constam do original.

4 Simmel se refere aqui, claro, à Soziologie, originalmente publicada em I908, e de que presente o excurso foi tirado.

5 Nessa passagem, como nas anteriores, "saber" traduz "Wissen" e "conhecer", “Erkennen". Simmel já empregara esses termos no parágrafo anterior, embora só aqui indique haver uma distinção entre os dois. Tentei traduzir esses termos (e seus correlatos) de modo uniforme, para assim comunicar em que momento Simmel emprega cada um dos termos aí distinguidos um do outro. Houve, porém, casos em que a aplicação dessa regra não se mostrou viável (em particular a tradução do verbo "wissen" por "saber", que simplesmente não se encaixou de forma inteligível em determinadas passagens); nesses casos, adaptei a tradução ao contexto mais imediato, e acrescentei, entre colchetes, no corpo do texto, a referência ao termo original.

6 Indiquei com os marcadores [a] e [b] as passagens do texto em que Simmel inicia a discussão de cada um desses "planos" em que se manifestariam os desvios a que se refere. Tais marcadores não constam do texto original.

7 Optei em acrescentar as aspas contidas nesse período, que não constam, portanto, do original.

8 A expressão latina terminus a quo significa "ponto de partida" ou, mais literalmente, o "termo do qual" [se vai, se parte]. Já a expressão terminus ad quem significa "ponto de chegada", ou seja, trata-se do "termo ao qual" [se vai, se dirige ou se chega]. Simmel emprega tais expressões, bem como outras com sentido análogo, diversas vezes ao longo do texto, sobretudo nesta seção. 
9 Optei em acrescentar o conteúdo entre colchetes para que fique mais claro a que Simmel, em cada caso, se refere.

Io A "formação" [Formung] (que tem aqui o sentido de uma "maneira de dar forma às coisas") a que Simmel aqui se refere é a tratada ao longo do parágrafo anterior, e por ele grifada, ali, em itálico.

I I Ou seja, segundo a qual uns seriam destinados para serem escravos, para servir, enquanto outros, para serem amos, senhores, enfim, para mandar (a palavra em grego " $\delta \varepsilon \sigma \pi$ ć $\varepsilon ı v$ " compartilha o mesmo radical que os termos "déspota" e "despotismo").

I 2 Termina aqui o jogo de palavras articulado por Simmel (perdido nesta tradução), que consiste em indicar o nexo etimológico entre o conceito de "profissão" [Beruf], o substantivo "chamado" [Ruf] e o verbo "nomear" ou "convocar" [berufen].

\section{REFERÊNCIAS BIBLIOGRÁFICAS}

Simmel, Georg. (2009). Inquiries into the construction of social forms. Leiden/Boston: Brill.

Simmel, Georg. (1998). Sociología: estudios sobre las formas de socialización. Madri: Alianza.

Simmel, Georg. (I9I0). How is society possible? American Journal of Sociology, XVI/3, p. 372-39I. 


\section{EXCURSO SOBRE O PROBLEMA: COMO É POSSÍVEL A SOCIEDADE?}

Resumo

Este texto foi originalmente publicado em I908, em alemão, como parte da Soziologie - considerada a obra sociológica maior de Simmel. Ofereço aqui uma tradução deste. No texto propriamente dito, o autor tem em vista descrever e investigar três condições a priori na base das quais a sociedade empírica como a conhecemos seria possível. O próprio autor apresenta a discussão como um esboço teórico. Este é guiado por uma série de comparações positivas e negativas entre a natureza segundo Kant e a sociedade, e aborda (de maneira não sistemática, mas bastante pioneira, considerando o estado da arte de seu tempo) diversas questões que se tornariam centrais para a teoria social que estava por vir.

\section{EXCURSUS ON THE PROBLEM: HOW IS SOCIETY POSSIBLE?}

Abstract

This text was originally published in 1908, in German, within Simmel's Soziologie - which is considered his major and investigate three a priori conditions upon which empirical society, as we know it, would be possible. Simmel himself framed the discussion as a theoretical draft. This draft is guided by a chain of positive and negative comparisons between nature according to Kant and society, and tackles (in a non-systematic, but fairly pioneer fashion, considering the epoch's state of the art) many questions that would turn out to be key ones to the social theory yet to come.
Palavras-chave

Georg Simmel;

Sociologia; Sociedade empírica; Teoria social; Neokantimo.

\section{Keywords}

Georg Simmel; Sociology; Empirical society; Social theory; Neo-kantianism. 